\title{
Kinetika Reaksi Reduksi Ion Logam Tembaga pada Limbah Industri Elektroplating dengan Proses Elektrokoagulasi
}

\author{
Emi Erawati*, Kesi Marfiana \\ Program Studi Teknik Kimia, Fakultas Teknik, Universitas Muhammadiyah Surakarta
}

Jl. A. Yani Tromol Pos I Pabelan, Kartasura, Surakarta, 57102, Indonesia

\author{
Artikel histori : \\ Diterima 8 September 2020 \\ Diterima dalam revisi 12 \\ September 2020 \\ Diterima 20 Oktober 2020 \\ Online 31 Oktober 2020
}

\begin{abstract}
ABSTRAK: Proses elektroplating selain menghasilkan produk yang berguna juga menghasilkan limbah. Tembaga merupakan salah satu unsur yang terkandung di dalam limbah. Limbah yang mengandung tembaga berdampak besar bagi lingkungan dan kesehatan manusia jika tidak ada pengolahan sebelumnya. Salah satu cara untuk menurunkan kadar tembaga pada limbah elektroplating yaitu dengan proses elektrokoagulasi. Penelitian ini bertujuan untuk mengetahui efisiensi penurunan konsentrasi limbah pada variasi konsentrasi dan jenis elektroda serta mengetahui konstanta laju reaksi reaksi orde satu dan dua. Limbah elektroplating diambil sebanyak 60, 80 dan $100 \mathrm{~mL}$ diencerkan dengan aquadest dilabu ukur $500 \mathrm{~mL}$. Kedua plat dijepit menggunakan statif dan plat tercelup 3/4 air limbah. Katoda dan anoda dihubungkan dengan power supply bertegangan 12 volt dengan jarak antar elektroda $2 \mathrm{~cm}$ dan kecepatan pengadukan $200 \mathrm{rpm}$. Sampel diambil setiap 0; 40; 80; 120; dan 160 menit untuk diuji kadar $\mathrm{Cu}$ dengan AAS. Mengulangi langkah yang sama pada variasi jenis elektroda yaitu $\mathrm{Al}, \mathrm{Fe}$, dan $\mathrm{CuZn}$. Efisiensi tertinggi pada variasi konsentrasi dan jenis elektroda sebesar $67,66 \%$ pada konsentrasi limbah $80 \mathrm{mg} / \mathrm{L}$ dan 92,82\% pada plat besi (Fe). Konstanta laju reaksi orde satu dan dua secara berurutan adalah $0,0096 \mathrm{~s}^{-1}$ dan $0,0058 \mathrm{ppm}^{-1} . \mathrm{s}^{-1}$
\end{abstract}

Kata Kunci: elektroplating; limbah cair; elektrokoagulasi; tembaga

\begin{abstract}
The electroplating process not only produces useful products but also produces waste. Copper is one of the elements contained in waste. Waste containing copper has a major impact on the environment and human health if there is no prior treatment. One way to reduce copper levels in electroplating waste is the electrocoagulation process. This study aims to investigate the efficiency of reducing the concentration of waste at various concentrations and types of electrodes and to determine the reaction rate constants of the first and second order reactions. 60, 80 and $100 \mathrm{~mL}$ electroplating waste were diluted with distilled water in a 500 $\mathrm{mL}$ measuring flask. The two plates were clamped using a statif and a $3 / 4$ plate immersed in wastewater. The cathode and anode are connected to a 12 volt power supply with a distance between the electrodes of $2 \mathrm{~cm}$ and a stirring speed of $200 \mathrm{rpm}$. Samples were taken every 0; 40; 80; 120; and 160 minutes to test $\mathrm{Cu}$ content with AAS. Repeating the same steps for various types of electrodes, namely $\mathrm{Al}, \mathrm{Fe}$, and $\mathrm{CuZn}$. The highest efficiency at various concentrations of $80 \mathrm{mg} / \mathrm{L}$ and types of electrodes of Fe were $67.66 \%$ and $92.82 \%$ in that order. The rate constants of the first and second order reactions are $0.0096 \mathrm{~s}^{-1}$ and $0.0058 \mathrm{ppm}^{-}$ ${ }^{1} . \mathrm{s}^{-1}$ respectively.
\end{abstract}

Keywords: electroplating; liquid waste; electrocoagulation; cuprum

\section{Pendahuluan}

Industri elektroplating di Indonesia mengalami perkembangan yang sangat pesat beberapa tahun terakhir, polusi air limbah elektroplating semakin meningkat (Nurhasni et al., 2018). Perkembangan industri logam yang semakin pesat tidak hanya memberikan manfaat tetapi juga memberikan dampak negatif dari limbah yang dihasilkan (Haroon, 2018). Industri elektroplating berpotensi menghasilkan limbah yang terdiri dari logam berat seperti kromium, tembaga, seng, kadmium, nikel, dan mangan (Mirsoleimani-Azizi, 2018).

Kuantitas limbah yang dihasilkan dalam proses elektroplating tidak terlampau besar tetapi tingkat toksisitasnya sangat berbahaya (El-Sheikh et al., 2018). Daya racun yang dimiliki menjadi penghalang kerja enzim, akibatnya proses metabolisme dalam tubuh akan terputus, penyebab alergi, mutagen, karsinogen bagi manusia yang biasanya masuk melalui kulit, pernapasan, dan pencernaan (Said, 2010). Pembuangan limbah secara langsung dari proses elektroplating ke lingkungan mengakibatkan

*Corresponding Author: +62-877-0920-2535; fax : +62-715-448

Email: emi.erawati@ums.ac.id 
pencemaran lingkungan dan juga pencemaran mikroorganisme (Fanani et al., 2017). Penurunan ion logam berat dari limbah cair dapat menggunakan metode elektrokoagulasi, elektrokimia, presipitasi kimia, ekstraksi pelarut, pertukaran ion, filtrasi membran, dan adsorpsi biomaterial (De Carvalho et al., 2015).

Pada penelitian ini menggunakan metode elektrokoagulasi. Metode elektrokoagulasi adalah sebuah proses elektrokimia, yang menggunakan arus listrik untuk menghilangkan logam dari larutan (Rafiq et al., 2014). Proses ini telah berhasil diterapkan untuk menghilangkan spesies ionik yang larut dalam suatu limbah dan penghilangan logam berat (Hasibuan, 2013). Metode ini merupakan metode yang efisien dan sederhana yang telah digunakan untuk pengolahan berbagai jenis air limbah seperti limbah elektroplating, limbah laundry, dan limbah pemotongan unggas (Bazrafshan et al., 2015). Proses elektrokoagulasi juga efektif untuk menghilangkan padatan tersuspensi, logam terlarut, tannin, dan pewarna (Liu, 2017)

Kelebihan metode elektrokoagulasi adalah peralatannya sederhana dan mudah dioperasikan serta efisiensi pengolahan yang dihasilkan cukup tinggi (Nofitasari and Samudro, 2014). Energi yang diperlukan rendah, volume yang dihasilkan relatif kecil, dan kualitas endapan sangat baik karena menghasilkan sedikit air ( Kabuk, 2014).

Teknologi elektrokoagulasi dapat meminimalisasi penggunaan bahan kimia (Jati, 2015).

Kinetika reaksi mempelajari laju reaksi secara kuantitatif. Laju reaksi kimia adalah jumlah mol reaktan per satuan volume yang bereaksi dalam waktu tertentu. Jika dibuat sebuah kurva penurunan konsentrasi reaktan sebagai fungsi waktu, maka akan diperoleh kurva bahwa slope kurvanya pada setiap titik selalu negatif, karena konsentrasi reaktan selalu menurun (Nath et al., 2015). Laju reaksi sepanjang kurva dapat dihitung dengan menggunakan persamaan $-\mathrm{dC} / \mathrm{dt}$.

$-\frac{d[A]}{d t}=k[A]$

$\ln \frac{[A] 0}{[A]}=k . t$

$-\frac{d[A]}{d t}=k[A]^{2}$

$\frac{1}{[A]}-\frac{1}{[A] 0}=k . t$

Keterangan :

(1) Persamaan reaksi orde satu

(2) Hasil integral dari persamaan (1) untuk memperoleh hubungan antara konsentrasi dengan waktu

(3) Persamaan reaksi orde dua

(4) Hasil integral dari persamaan (2) untuk memperoleh hubungan antara konsentrasi dengan waktu

Berdasarkan uraian tersebut peneliti tertarik untuk melakukan penelitian tentang penurunan kadar logam $\mathrm{Cu}$ dengan metode elektrokoagulasi dengan menggunakan variasi konsentrasi limbah dan jenis elektroda. Juga menentukan konstanta kecepatan reaksi reduksi limbah elektroplating dengan menggunakan orde satu dan orde dua.

\section{Metode Penelitian}

Pada penelitian ini bahan yang digunakan yaitu limbah elektroplating dan aquadest. Sedangkan $\mathrm{H}_{2} \mathrm{SO}_{4}$ dan $\mathrm{CuSO}_{4}$ untuk pembuatan larutan standar.

Alat-alat yang digunakan dalam penelitian ini adalah rangkaian alat elektrokoagulasi, plat logam alumunium (Al), besi $(\mathrm{Fe})$, dan plat kuningan sebagai elektroda proses elektrokoagulasi.

Limbah elektroplating diambil sebanyak 60, 80 dan 100 $\mathrm{mL}$ diencerkan dengan aquadest dilabu ukur $500 \mathrm{~mL}$. Limbah yang sudah diencerkan dimasukkan ke gelas beker $500 \mathrm{~mL}$ dan gelas beker sebagai bak elektrokoagulasi. Kedua plat dijepit menggunakan statif dan plat tercelup 3/4 air limbah. Katoda dan anoda dihubungkan dengan power supply bertegangan 12 volt dengan jarak antar elektroda 2 $\mathrm{cm}$ dan kecepatan pengadukan $200 \mathrm{rpm}$. Jenis elektroda divariasikan yakni plat alumunium, besi, dan kuningan. Sampel diambil setiap 0; 40; 80; 120; dan 160 menit untuk diuji kadar $\mathrm{Cu}$ dengan AAS. Mengulangi langkah yang sama pada variasi jenis elektroda yaitu $\mathrm{Al}, \mathrm{Fe}$, dan $\mathrm{CuZn}$.

Efisiensi penurunan limbah logam bisa dihitung dengan rumus

konsentrasi awal-konsentrasi akhir konsentrasi awal x $100 \%$

\section{Pembahasan}

\subsection{Pengaruh Variasi Konsentrasi Limbah Terhadap Penurunan Logam $\mathrm{Cu}$}

Penurunan efisiensi logam $\mathrm{Cu}$ pada variasi konsentrasi 60, 80, dan $100 \mathrm{mg} / \mathrm{L}$ dapat dilihat pada Tabel 1.

Tabel 1. Pengaruh Konsentrasi terhadap \% Efisiensi Penurunan Logam $\mathrm{Cu}$

\begin{tabular}{cccc}
\hline \multirow{2}{*}{$\begin{array}{c}\text { Waktu } \\
\text { (menit) }\end{array}$} & \multicolumn{3}{c}{ Efisiensi penurunan $\mathrm{Cu}(\%)$} \\
\cline { 2 - 4 } & $60 \mathrm{mg} / \mathrm{L}$ & $80 \mathrm{mg} / \mathrm{L}$ & $100 \mathrm{mg} / \mathrm{L}$ \\
\hline 0 & 0 & 0 & 0 \\
40 & 23,16 & 17,54 & 31,27 \\
80 & 37,22 & 43,64 & 35,69 \\
120 & 58,7 & 47,09 & 37,38 \\
160 & 60,37 & 67,66 & 50,34 \\
\hline
\end{tabular}

Pada Tabel 1 merupakan tabel nilai penurunan konsentrasi dan besar efisiensi tiap pengambilan sampel 40 menit. Terlihat bahwa semakin lama waktu proses elektrokoagulasi maka akan semakin besar pula efisiensi terkoagulasi yang dihasilkan. Pada konsentrasi limbah $\quad 80$ $\mathrm{mg} / \mathrm{L}$ dan pada menit ke-160 dapat dilihat bahwa efisiensinya paling tinggi yaitu 67,66\%. Pada variasi konsentrasi limbah $60 \mathrm{mg} / \mathrm{L}$ dengan kecepatan pengadukan konstan yaitu $200 \mathrm{rpm}$ didapat efisiensi yang semakin tinggi, yaitu dari $0 ; 23,16 ; 37,22 ; 58,70 ;$ dan 60,37\%. Namun ketika konsentrasi limbah dinaikkan menjadi $80 \mathrm{mg} / \mathrm{L}$ maka efisiensi penurunannya adalah $0 ; 17,54 ; 43,64 ; 47,06$; dan $67,66 \%$. Begitu juga pada konsentrasi limbah $100 \mathrm{mg} / \mathrm{L}$ semakin lama waktu kontak efisiensi penurunannya juga 
semakin tinggi yaitu dari $0 ; 31,27 ; 35,69 ; 37,38 ;$ dan $50,35 \%$.

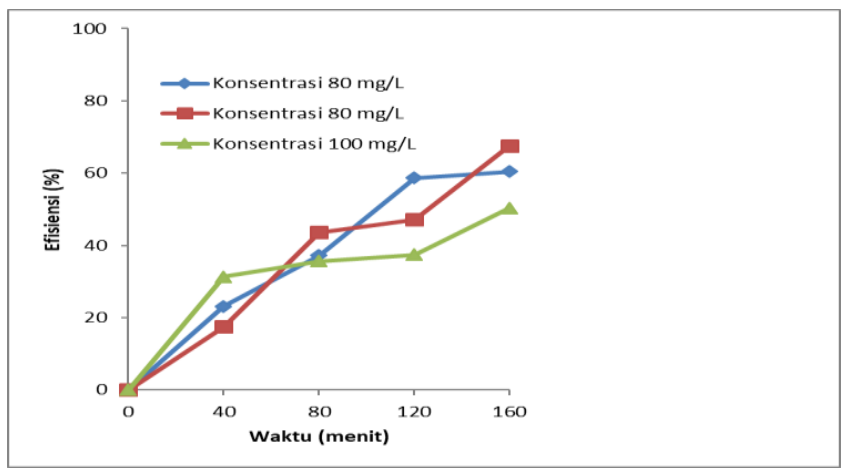

Gambar 1. Efisiensi pada variasi konsentrasi. Note:

$$
\diamond=60, \boldsymbol{\square}=80, \boldsymbol{\Delta}=100 \mathrm{mg} / \mathrm{L}
$$

Apabila ditinjau dari Hukum Faraday yang menyatakan bahwa semakin lama waktu elektrokoagulasi maka logam yang terendap akan semakin banyak (Wahyulis et al., 2014). Hal ini terjadi karena adanya proses terbentuknya koagulan yang mempengaruhi tereduksinya logam yang terkandung dalam sampel. Jika elektrokoagulasi dilakukan dalam waktu yang lama maka akan terjadi pengeroposan elektroda yang dapat menambah konsentrasi logam dalam sampel. Efisiensi tertinggi yang didapat dari ketiga variasi konsentrasi tersebut yaitu pada konsentrasi $80 \mathrm{mg} / \mathrm{L}$ dengan waktu kontak selama 160 menit.

\subsection{Pengaruh Variasi Jenis Elektroda terhadap Penurunan Logam Cu}

Tabel 2 menunjukkan efisiensi penurunan $\mathrm{Cu}$ pada variasi jenis elektroda yaitu Al, CuZn, dan Fe.

Tabel 2. Pengaruh Konsentrasi terhadap \% Efisiensi Penurunan Logam $\mathrm{Cu}$

\begin{tabular}{cccc}
\hline \multirow{2}{*}{$\begin{array}{c}\text { Waktu } \\
\text { (menit) }\end{array}$} & \multicolumn{3}{c}{ Efisiensi Penurunan $\mathrm{Cu}(\%)$} \\
\cline { 2 - 4 } & $\mathrm{Al}$ & $\mathrm{CuZn}$ & $\mathrm{Fe}$ \\
\hline 0 & 0 & 0 & 0 \\
40 & 17,54 & 43,82 & 47,41 \\
80 & 43,64 & 57,27 & 65,94 \\
120 & 47,09 & 66,36 & 91,82 \\
160 & 67,66 & 80,91 & 92,82 \\
\hline
\end{tabular}

Dipilihnya plat alumunium karena sifatnya yang baik dalam menghantarkan listrik dan anti korosi. Plat Al juga berikatan dengan $\mathrm{OH}^{-}$sehingga akan membentuk koagulan yang baik. Pada variasi elektroda Al di peroleh efisiensi tertinggi sebesar $67,66 \%$. Efisiensi menggunakan elektroda Al paling rendah karena tegangan yang digunakan rendah yaitu 12 volt. Karena tegangan rendah maka mengakibatkan suplai tegangan untuk pembentukan $\mathrm{Al}(\mathrm{OH})_{3}$ kurang efektif.

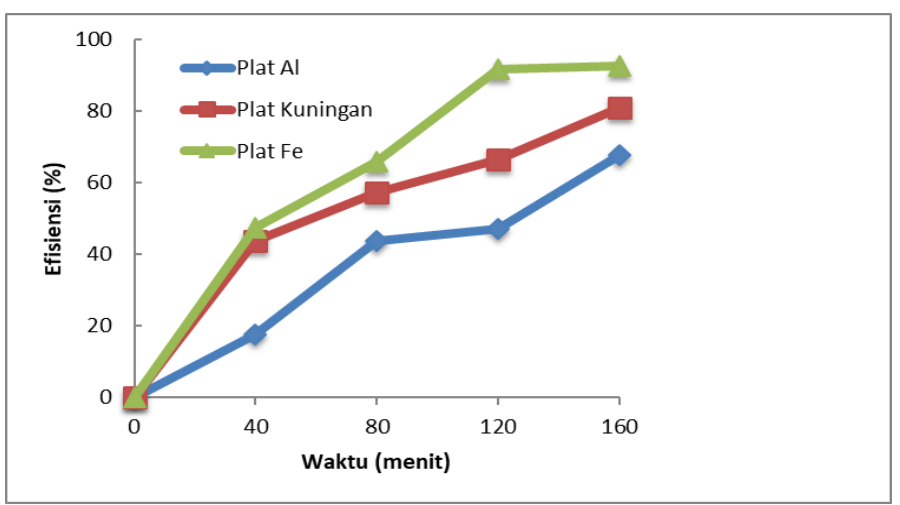

Gambar 2. Efisiensi pada variasi jenis elektroda. Note: $\bullet=$ Plat

$$
\mathrm{Al}, \mathbf{\square}=\mathrm{CuZn}, \boldsymbol{\Delta}=\mathrm{Fe}
$$

Pada variasi elektroda Fe menghasilkan efisiensi yang paling tinggi sebesar $92,82 \%$ sehingga elektroda yang paling efektif yaitu elektroda Fe. Pada proses elektrokoagulasi ini terjadi flok-flok yang terapung, hal ini sebagai indikasi bahwa ion $\mathrm{Fe}^{3+}$ mengikat polutan atau pengotor sangat efektif. Jumlah flok semakin bertambah membuat sebagian flok menutupi plat elektroda dan menghalangi kemampuan elektroda untuk menarik ion tembaga dari limbah, sehingga terjadi penurunan kuat medan magnet yang berdampak terjadinya penurunan efisiensi. Begitu juga dengan menggunakan elektroda kuningan, efisiensi yang tertinggi terdapat pada waktu kontak ke 160 menit dengan \% efisiensi sebesar $80,91 \%$. Dari pengaruh waktu saat diketahui bahwa waktu terbaik yang menghasilkan efisiensi penurunan konsentrasi tembaga adalah 160 menit. Waktu kontak antara limbah dan elektroda dalam proses elektrokoagulasi mempengaruhi penurunan kadar tembaga. Semakin lama waktu kontak maka semakin lama air limbah bereaksi dengan elektroda sehingga mempengaruhi efisiensi removalnya. Tetapi kemampuan elektroda dalam mereduksi air limbah terbatas ,meskipun waktu kontak diperlama apabila reaksi antara elektroda dengan air limbah sudah jenuh kemampuan elektrodanya berkurang.

\subsection{Kinetika Reaksi}

Untuk mencari orde reaksi dibuat sebuah tabel yang menghitung besarnya konstanta laju reaksi (k) untuk setiap orde reaksi, kemudian dari hasil ini dihitung error atau kesalahan dari konstanta laju reaksi. Berikut merupakan orde reaksi pada variasi konsentrasi $60,80,100 \mathrm{mg} / \mathrm{L}$ dan jenis elektroda alumunium ( $\mathrm{Al})$, kuningan $(\mathrm{CuZn})$, besi $(\mathrm{Fe})$.

Sebuah kurva penurunan konsentrasi reaktan sebagai fungsi waktu, maka akan diperoleh kurva bahwa slope kurvanya pada setiap titik selalu negatif, karena konsentrasi reaktan selalu menurun. Jadi laju reaksi pada setiap titik sepanjang kurva $=-\mathrm{dC} / \mathrm{dt}$. Tetapi apabila laju reaksi dituliskan sebagai laju pembentukan produk, maka laju reaksi akan bernilai positif. Orde reaksi adalah jumlah pangkat konsentrasi dalam bentuk diferensial. Secara teoritis orde reaksi merupakan bilangan bulat kecil, namun dalam beberapa hal pecahan atau nol. Pada umumnya orde reaksi terhadap suatu zat tertentu tidak sama dengan 
koefisien dalam persamaan stoikiometri reaksi (Nath, et al., 2015).

Reaksi orde 1 dapat dihitung dengan menggunakan rumus $\ln \mathrm{C}_{\mathrm{o}} / \mathrm{C}_{\mathrm{t}}$ dimana $\mathrm{C}_{\mathrm{o}}$ merupakan konsentrasi mulamula sebelum diberi perlakuan apapun, dan $C_{t}$ merupakan konsentrasi diwaktu tertentu.

Tabel 3. Parameter Kinetika Reaksi Reduksi Orde Satu

\begin{tabular}{llcc}
\hline Variasi & & $\mathbf{k}\left(\mathbf{s}^{\mathbf{- 1}}\right)$ & $\mathbf{R}^{\mathbf{2}}$ \\
\hline Konsentrasi & $60 \mathrm{mg} / \mathrm{L}$ & 0,0062 & 0,965 \\
& $80 \mathrm{mg} / \mathrm{L}$ & 0,0068 & 0,957 \\
& $100 \mathrm{mg} / \mathrm{L}$ & 0,0037 & 0,864 \\
Jenis Elektroda & $\mathrm{Al}-\mathrm{Al}$ & 0,0068 & 0,957 \\
& $\mathrm{CuZn}-\mathrm{CuZn}$ & 0,0096 & 0,974 \\
& $\mathrm{Fe}-\mathrm{Fe}$ & 0,0178 & 0,946 \\
\hline
\end{tabular}

Dari data Tabel 3 diperoleh nilai $\mathrm{R}^{2}$ yang mendekati 1 yaitu pada variasi konsetrasi $60 \mathrm{mg} / \mathrm{L}$ dengan konstanta laju reaksi (k) sebesar $0,0062 \mathrm{~s}^{-1}$ dan pada variasi jenis elektroda plat kuningan $(\mathrm{CuZn})$ dengan konstanta laju reaksi $(\mathrm{k})$ sebesar $0,0096 \mathrm{~s}^{-1}$.

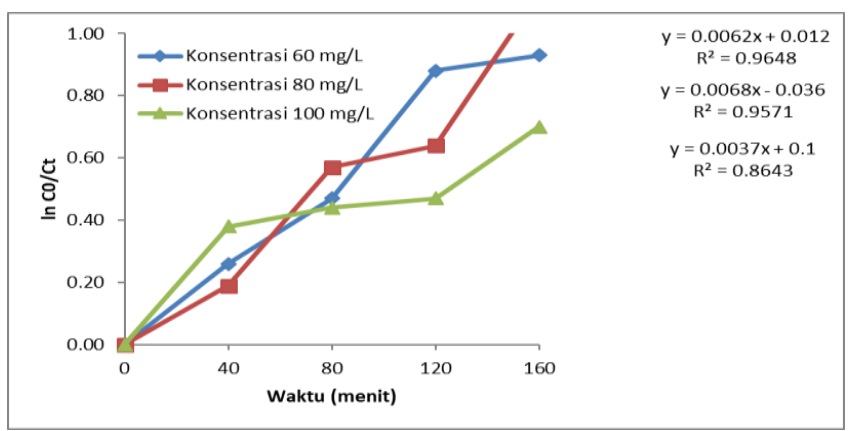

Gambar 3. Kurva proses elektrokoagulasi kadar tembaga variasi konsentrasi orde satu. Note:

$=60$

$80, \boldsymbol{\Delta}=100 \mathrm{mg} / \mathrm{L}$.

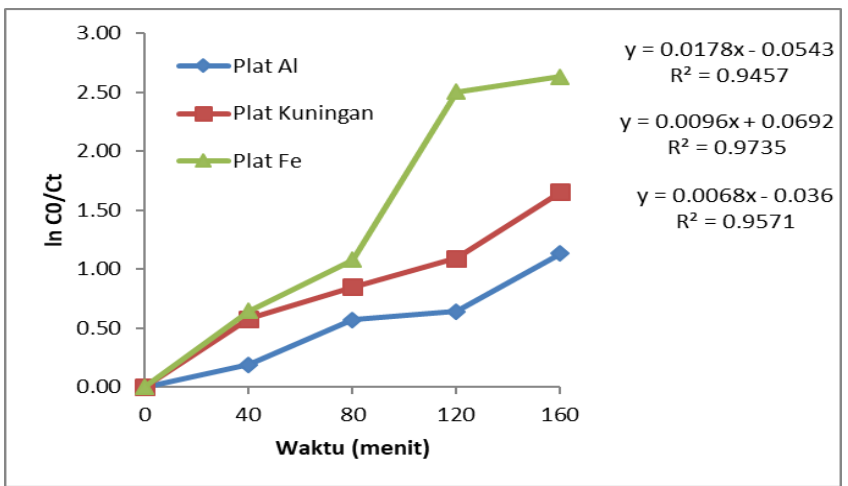

Gambar 4. Kurva proses elektrokoagulasi kadar tembaga variasi jenis elektroda orde satu. Note: $\bullet=$ Plat $\mathrm{Al}, \boldsymbol{\nabla}=\mathrm{CuZn}, \boldsymbol{\Delta}=\mathrm{Fe}$.

Pengujian model kinetika dengan metode grafik dari persamaan (2) untuk orde satu dan persamaan (4) untuk orde dua, serta dilinierkan dapat diketahui hasil percobaan dengan variasi konsentrasi dan jenis elektroda dilihat pada (Gambar 3 dan Gambar 4) untuk orde satu dan (Gambar 5 dan Gambar 6) untuk orde dua. Prediksi penentuan konstanta reaksi dapat dilihat dari nilai $\mathrm{R}^{2}$ dengan nilai yang saling mendekati dan seragam (Prasetyaningrum, et al., 2018)

Bagitu pula pada reaksi orde 2 dapat dihitung dengan menggunakan rumus $1 / \mathrm{C}_{\mathrm{t}}-1 / \mathrm{C}_{0}$ dimana $\mathrm{Co}$ merupakan konsentrasi mula-mula sebelum diberi perlakuan apapun dan $\mathrm{C}_{\mathrm{t}}$ adalah konsentrasi limbah pada waktu tertentu.

Tabel 4. Parameter Kinetika Reaksi Reduksi Orde Dua

\begin{tabular}{llcc}
\hline Variasi & & $\mathbf{k}\left(\mathbf{p p m}^{-\mathbf{1}} \mathbf{s}^{\mathbf{- 1}}\right)$ & $\mathbf{R}^{\mathbf{2}}$ \\
\hline Konsentrasi & $60 \mathrm{mg} / \mathrm{L}$ & 0,0058 & 0,946 \\
& $80 \mathrm{mg} / \mathrm{L}$ & 0,0031 & 0,887 \\
\multirow{3}{*}{ Jenis Elektroda } & $100 \mathrm{mg} / \mathrm{L}$ & 0,0021 & 0,901 \\
& $\mathrm{Al}-\mathrm{Al}$ & 0,0031 & 0,887 \\
& $\mathrm{CuZn}-$ & 0,4395 & 0,901 \\
& $\mathrm{CuZn}$ & 1,5102 & 0,861 \\
\hline
\end{tabular}

Berdasarkan data Tabel 4 diperoleh nilai $\mathrm{R}^{2}$ mendekati 1 yaitu pada konsentrasi $60 \mathrm{mg} / \mathrm{L}$ dengan konstanta laju reaksi (k) sebesar $0,0058 \mathrm{ppm}^{-1} \cdot \mathrm{s}^{-1}$ dan pada jenis elektroda plat kuningan dengan konstanta laju reaksi $(\mathrm{k})$ sebesar 0,4395 $\mathrm{ppm}^{-1} \cdot \mathrm{s}^{-1}$.

Berdasarkan Tabel 3 dan Tabel 4 pada proses elektrokoagulasi limbah industri elektroplating diperoleh harga konstanta kecepatan reaksi sebesar $0,0096 \mathrm{~s}^{-1}$ dengan harga $\mathrm{R}^{2} 0,974$. Sehingga proses elektrokoagulasi limbah industri elektroplating lebih sesuai diprediksi dengan menggunakan orde 1 .

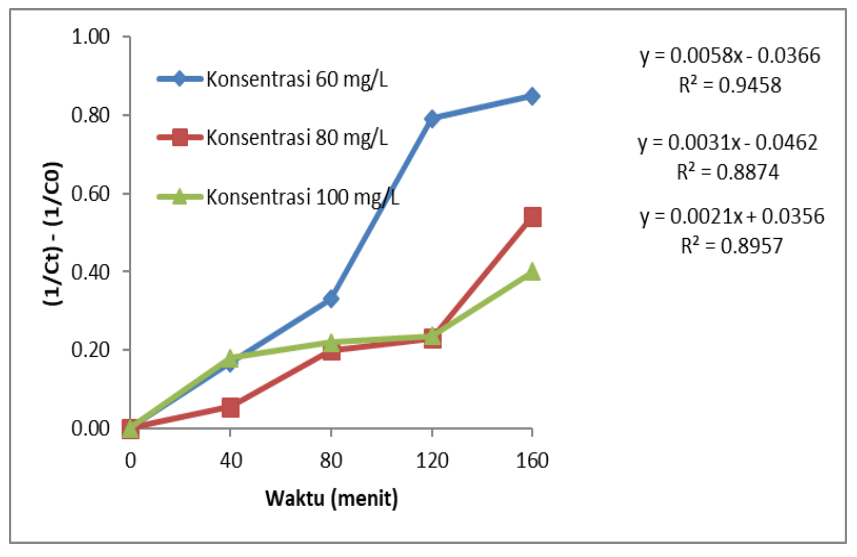

Gambar 5. Kurva proses elektrokoagulasi kadar tembaga variasi konsentrasi orde dua. Note: $\diamond=60$, $80, \boldsymbol{\Delta}=100 \mathrm{mg} / \mathrm{L}$. 


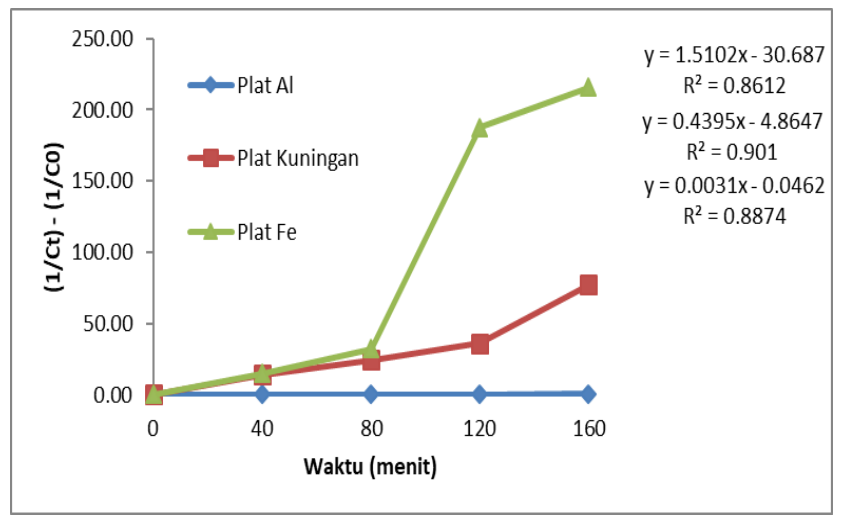

Gambar 6. Kurva proses elektrokoagulasi kadar tembaga variasi jenis elektroda orde dua. Note: $\bullet=$ Plat $\mathrm{Al}, \boldsymbol{\nabla}=\mathrm{CuZn}, \boldsymbol{\Delta}=\mathrm{Fe}$.

Harga konstanta laju reaksi pada beberapa penelitian dengan metode elektrokoagulasi ditampilkan pada Tabel 5.

Tabel 5. Konstanta laju reaksi dari beberapa penelitian

\begin{tabular}{clccc}
\hline Peneliti & \multicolumn{1}{c}{ Limbah } & $\mathrm{K}\left(\mathrm{s}^{-1}\right)$ & $\mathrm{n}$ & $\mathrm{R}^{2}$ \\
\hline $\begin{array}{c}\text { (Prayitno, } \\
\text { 2007) }\end{array}$ & Laundry & 0,014 & 1 & 0,9983 \\
$\begin{array}{c}\text { (Kundari } \\
\text { et al., }\end{array}$ & $\begin{array}{l}\text { Cair } \\
\text { Pelapisan }\end{array}$ & 0,0006 & 1 & 0,9994 \\
$\begin{array}{l}\text { 2009) } \\
\text { (Santoso et }\end{array}$ & $\begin{array}{l}\text { Logam } \\
\text { Laboratorium }\end{array}$ & 0,042 & 1 & 0.99 \\
$\begin{array}{c}\text { (Ridantami } \\
\text { et al., }\end{array}$ & Elektroplating & 0,005 & 1 & 0,996 \\
2017) & & & & \\
\hline
\end{tabular}

\section{Kesimpulan}

Elektrokoagulasi dipengaruhi oleh besarnya konsentrasi limbah dan jenis elektroda. Pada variasi konsentrasi dan jenis elektroda efisiensi tertinggi adalah sebesar $67,66 \%$ dan $92,82 \%$. Kinetika reaksi reduksi limbah $\mathrm{Cu}$ sesuai dengan kinetika reaksi orde satu dengan konstanta kecepatan reaksi sebesar $0,0096 \mathrm{~s}^{-1}$.

\section{Daftar Pustaka}

Bazrafshan, E., Leili, M., Alireza, M., and Amir, H. M., 2015 , Environmental health heavy metals removal from aqueous environments by electrocoagulation process - a systematic review, Journal of Environmental Health Science and Engineering.

De Carvalho, Helder, P., Jiguo, H., Meixia, Z., Gang, L., Lili, D., and Xingjuan, L., 2015, Improvement of methyl ene blue removal by electrocoagulation/banana peel adsorption coupling in a batch system, Alexandria Engineering Journal, Vol. 54. No.3: 777-86.

El-Sheikh, I. F.-S., 2018, Immobilization of citric acid and mangnetite on sawdust for competitive adsorption and extraction of metal ions from environmental waters.
Journal of Environmental Chemical Engineering: 51865195.

Fanani, A. S., 2017, Pemanfaatan biomassa alga biru-hijau anabaena cycadae dalam proses bisorpsi logam $\mathrm{Cr}$ pada limbah cair industri elektroplating. Jurnal Fakultas Teknik: 1-5.

Haroon, M., 2018, Synthesis of carboxymethyl starch-gpolyvinylpyrolidones and their properties for the adsorption of Rhodamine $6 \mathrm{G}$ and ammonia. Carbohydrate Polymers: 150-158.

Hasibuan, S., 2013, Improving the quality of tofu waste as a source of feed through fermentation using the bacillus amyloliquefaciens culture: 22-25.

Jati, Bumiarto Nugroho, 2015, Kombinasi teknologi elektrokoagulasi dan fotokatalisis dalam mereduksi limbah berbahaya dan beracun cr (VI), Vol. 37. No. 2:133-40.

Kabuk, H. A., 2014, Investigation of leachate treatment with electrocoagulation and optimization by response surface methodology. Clean - Soil, Air, Water: 571-577.

Kundari, N.A., Nurmaya, A., and Kartin, M. Kinetika, 2009, Reduksi Krom (VI) dalam limbah cair industri pelapisan logam. Seminar Nasional V SDM Teknologi Nuklir, Yogyakarta.

Liu, S. Simultaneous, 2017, Removal of Ni(II) and fluoride from a real flue gas desulfurization wastewater by electrocoagulation using $\mathrm{Fe} / \mathrm{C} / \mathrm{Al}$ electrode. Journal of Water Reuse and Desalination: 288-297.

Mirsoleimani-Azizi, S. M., 2018, Aqueous solution by electrocoagulation process using artificial neural network (ann). Industrial and Engineering Chemistry Research: 150-158.

Nath, B., Fabrication, F., Project, F., \& Complex, N. F., 2015, Study on thorium removal effulenythorium removal. removal from effluent. International Thorium Energi. Conference - ThEC15.

Nofitasari, R., and Ganjar, S., 2014, Studi penurunan konsentrasi nikel dan tembaga pada limbah cair elektroplating dengan metode elektrokoagulasi: 1-8.

Nurhasni, Zainus, S., and Ita, N., 2018, Pengolahan limbah industri elektroplating dengan proses koagulasi flokulasi. Jurnal Kimia VALENSI: 41-48.

Prasetyaningrum, A., Dharmawan, Y., Djaeni, M., Eka, E. S., and Eltiara, I. V., 2018, Seminar nasional kolaborasi peningkatan efisiensi pengolahan limbah elektroplating melalui proses koagulasi-flokulasi: 261-63.

Prayitno, P., 2007, Kajian kinetika kimia model matematik reduksi kadmium melalui laju reaksi, konstante dan orde reaksi dalam proses elektrokimia. GANENDRA Majalah IPTEK Nuklir: Vol. 10. No.1

Rafiq, Z., Rabia, N., Raza, M., and Shujat, A., 2014, Utilization of magnesium and zinc oxide nanoadsorbents as potential materials for treatment of copper electroplating industry wastewater. Journal of Environmental Chemical Engineering Biochemical Pharmacology, Vol. 2. No. 1: 642-51.

Ridantami, V., Wasito, B., and Prayitno, P., 2017, Model matematik reduksi thorium dalam proses 
elektrokoagulasi. Eksplorium: Buletin Pusat Teknologi Bahan Galian Nuklir: 121-132.

Said, Nusa, I., 2010, Metoda penghilangan logam berat (As, $\mathrm{Cd}, \mathrm{Cr}, \mathrm{Ag}, \mathrm{Cu}, \mathrm{Pd}, \mathrm{Ni}, \mathrm{Dan} \mathrm{Zn})$ di dalam air limbah Industri." Jai, Vol. 6. No. 2: 136-48.

Santoso, U. T., Herdiansyah, H., Trisunaryanti, W., and Santosa, S. J., 2014, Study on the rate of reduction of $\mathrm{Cr}$ (VI) to $\mathrm{Cr}$ (III) by humic acid using continum multicomponent model, Indonesian Journal of Chemistry, Vol. 4. No. 1: 12-25.

Wahyulis., Chanifa, N., Ita, U., and Harmami, 2014, Optimasi tegangan pada proses elektrokoaglasi penurunan kadar kromium dari filtrat hasil hidrolisis limbah padat penyamakan kulit, Jurnal Sains Dan Seni POMITS, Vol. 3. No. 2: 9-11. 